\title{
Remarkable Clinical Improvement Following Microsurgical Resection of Left Lingual Gyrus Cerebral Cavernous Malformation: A Case Report
}

\author{
Samer S. Hoz ${ }^{1}$ Zahraa F. Al-Sharshahi ${ }^{1}$ Mustafa M. Altaweel ${ }^{1} \quad$ Saja A. Albanaa ${ }^{2}$ \\ ${ }^{1}$ Department of Neurosurgery, Neurosurgery Teaching Hospital, \\ Baghdad, Iraq \\ ${ }^{2}$ College of Medicine, Baghdad University, Baghdad, Iraq \\ Address for correspondence Zahraa Al-Sharshahi, MB, BCh, BAO (NUI, \\ RCSI), LRCP \& SI, Department of Neurosurgery, Neurosurgery Teaching \\ Hospital, Baghdad, Iraq (e-mail: zahraaalsharshahi@rcsi.com).
}

Arq Bras Neurocir 2021;40(3):e268-e271.

Abstract
Keywords
- cerebral cavernous
malformations
- left lingual gyrus
- microsurgical
resection

Introduction Cerebral cavernous malformations (CCMs) are collections of dilated and irregular capillaries in the brain. Cerebral cavernous malformations are predominantly supratentorial; occipital CCMs are rare. Surgical removal is indicated for CCMs with recurrent hemorrhage, refractory seizures, and expanding lesions.

Case Description We describe a case of a 15-year-old male who presented with repeated tonic-clonic seizures and right homonymous hemianopia of 3-week duration. Magnetic resonance imaging (MRI) showed a mass located on the left medial occipital lobe, specifically in the left lingual gyrus. The T2-weighted and T2-gradient echo images confirmed the diagnosis of a CCM. Total microscopic resection was achieved. There were no surgical complications. The visual deficit improved, and the patient was seizure-free on subsequent follow-up visits.

Conclusion Surgical resection of an occipital CCM resulted in a remarkable improvement in terms of seizures and visual field deficits.

\section{Introduction}

Cerebral cavernous malformations (CCMs) represent up to $15 \%$ of cerebral vascular lesions. ${ }^{1}$ Eighty percent of CCMs have supratentorial location with the frontal and temporal lobes being the most common. ${ }^{2}$ Cerebral cavernous malformations commonly present during the $2^{\text {nd }}$ through to the $5^{\text {th }}$ decades of life. ${ }^{3}$ Convulsions, neurological deficits and bleeding are the most common forms of presentation of CCMs. ${ }^{4,5}$ Surgical removal is the treatment of choice for supratentorial CCMs, particularly in enlarging lesions, medically refractory seizures or lesions with recurrent hemorrhages. ${ }^{6}$ The occipital lobe represents a rare site for CCMs and microsurgical resection is challenging especially for medial occipital lesions due to their proximity to the eloquent visual areas

received

April 4, 2020

accepted

August 5, 2020

published online

October 16, 2020 around the calcarine sulcus. In addition, the bridging veins may represent an obstacle during the occipital interhemispheric approach. ${ }^{2}$ Reports on the outcomes of CCMs in this location are scarce. Here, we present a case report on a surgically-treated medial occipital CCM with complete resolution of both visual deficits and seizures.

\section{Case Description}

A 15-year-old, right-handed male presented with repeated seizures of 3-month duration and right homonymous hemianopia of 3-week duration. The seizures were generalized tonic-clonic, occurred at a frequency of three times per week. The patient was on dual anti-epileptic medications, namely carbamazepine and sodium valproate, at maximum doses. On

\footnotetext{
(c) 2020. Sociedade Brasileira de Neurocirurgia. All rights reserved. This is an open access article published by Thieme under the terms of the Creative Commons Attribution-NonDerivative-NonCommercial-License, permitting copying and reproduction so long as the original work is given appropriate credit. Contents may not be used for commercial purposes, or adapted, remixed, transformed or built upon. (https://creativecommons.org/ licenses/by-nc-nd/4.0/) Thieme Revinter Publicações Ltda., Rua do Matoso 170, Rio de Janeiro, RJ, CEP 20270-135, Brazil
} 
examination, the patient was conscious, oriented, and had no weakness. Ophthalmological and visual field assessment revealed a right homonymous hemianopia with intact optic disc and ocular motility with no visual hallucination, alexia nor agraphia. Cranial CT scan showed a left medial occipital mass of mixed density (hypo- and hyperdense) without a surrounding brain edema. Magnetic resonance imaging (MRI) showed a mass located on the left medial occipital lobe, specifically in the left lingual gyrus (medial occipitotemporal gyrus). The T2-wighted and T2-gradient echo images showed a mixed intensity core (popcorn appearance), which represents hemorrhages at different stages. This lesion was surrounded by a hypointense rim that represented the characteristic hemosiderin ring around the CCM (old hemorrhage). The mass was nonenhancing and there was no surrounding edema (-Fig. 1). Electroencephalography (EEG) showed epileptiform discharges localized in the left occipital lobe. Total microsurgical resection of the CCM was achieved through the left occipital interhemispheric approach, in prone position. The surrounding cortex and adjacent bridging veins were preserved (-Fig. 2). A postoperative MRI confirmed the complete resection of the CCM (-Fig. 3). The pathology report revealed dilated, cystic spaces lined by endothelial cells filled with blood with thick fibrous walls and hemosiderin laden macrophages, a picture consistent with a CCM. The surgery was uneventful and the patient was discharged at 5 days postoperatively. At his 1-month follow-up visit, the patient reported a complete resolution of the visual deficits, and this was confirmed by ophthalmological examination and visual field assessment. The patient was continued on his dual anti-epileptic medications over the next 3 months; the medications were then tapered slowly over the course of 6 months, and were stopped completely at 9 months postdischarge. At the 22-month follow-up visit, the EEG was normal, and the patient was not taking any anti-epileptic medications and his postoperative seizure score (Engle score) was class one (seizure-free).

\section{Discussion}

Cerebral cavernous malformations are mulberry-like, benign lesions representing dilated vascular channels with no intervening brain parenchyma. ${ }^{7}$ The incidence of CCMs in the general population is of $0.5 \%{ }^{8}$ Cerebral cavernous malformations can be familial $(20 \%)$ or sporadic $(80 \%) .{ }^{9}$ Familial CMMs are inherited in an autosomal dominant manner,
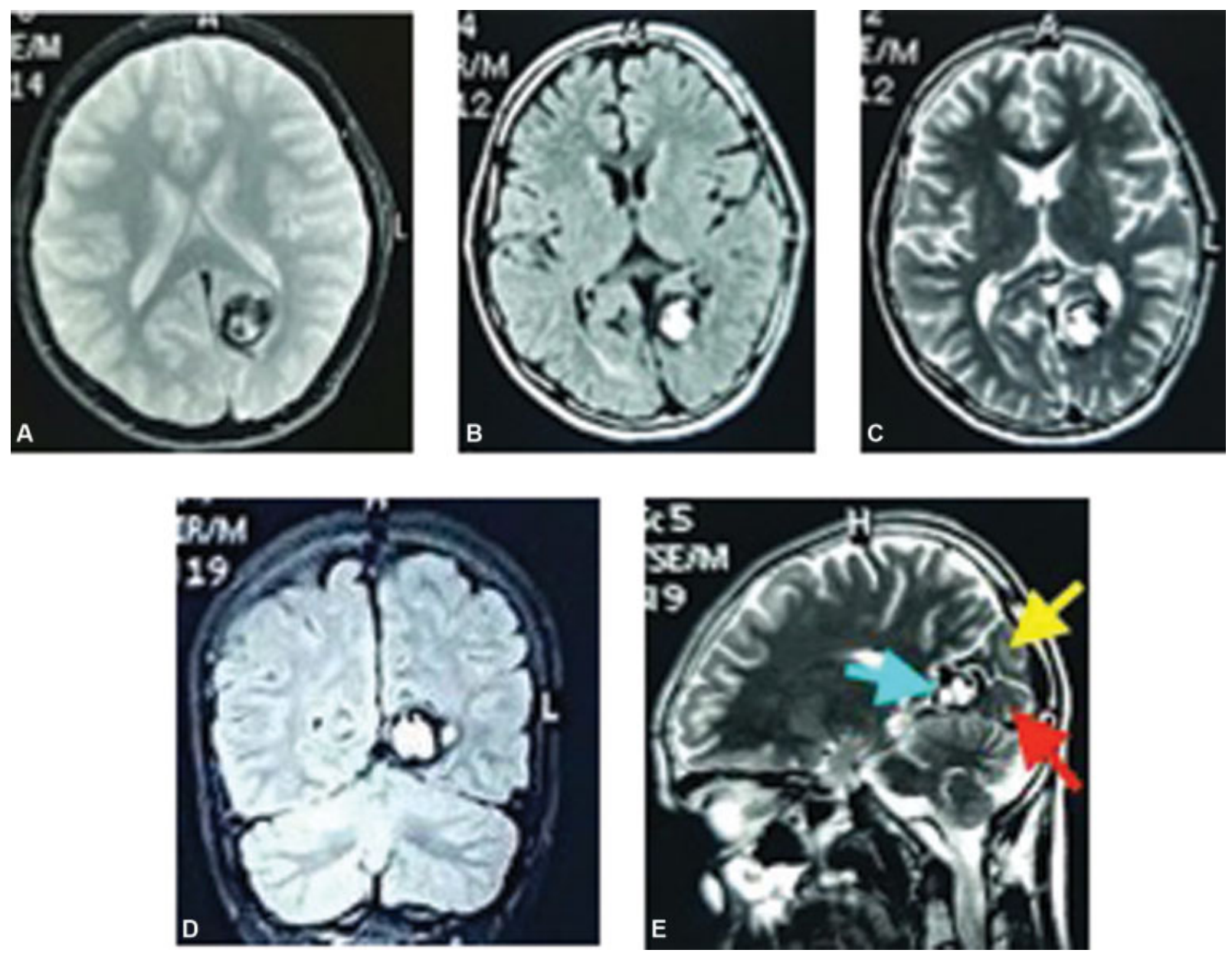

Fig. 1 Preoperative magnetic resonance imaging studies: A,B,C (T2-gradient Echo, FLAIR, and T2 images, respectively), showing a left medial occipital cavernoma with mixed intensity core (popcorn appearance) surrounded by a hypointense hemosiderin ring, with no surrounding edema. D: Coronal view showing the proximity of CCM to the medial surface. E: Sagittal view showing the exact location of the CCM at the left lingual gyrus; red arrow: lingual gyrus, yellow arrow: cuneus, blue arrow: the cavernoma. 


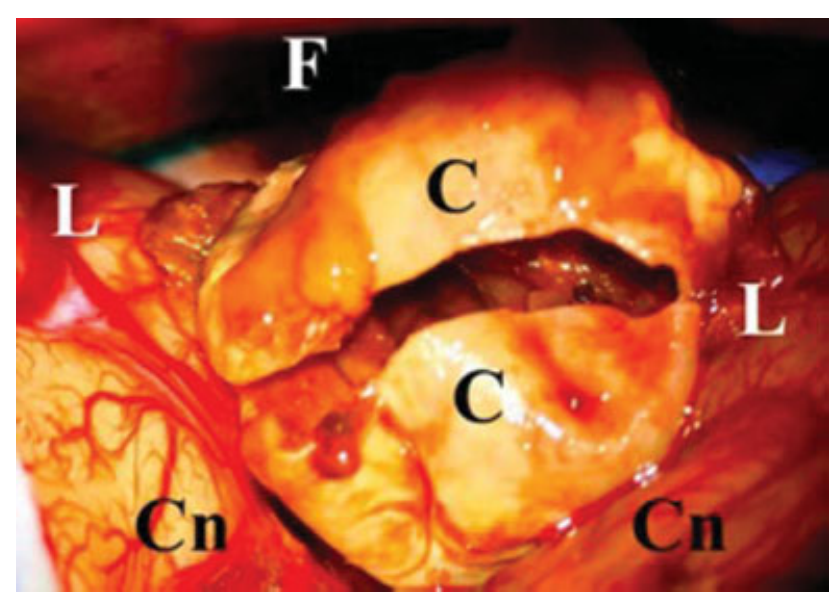

Fig. 2 An intraoperative image through the left occipital approach (prone position) showing the medial occipital cerebral cavernous malformation (CCM) in-situ, after initial dissection from the surrounding cortex. In this image, the CCM has a thick wall and is opened for internal decompression. C:CCM; Cn: Cuneus; F: Falx cerebri; L: Lingual gyrus.
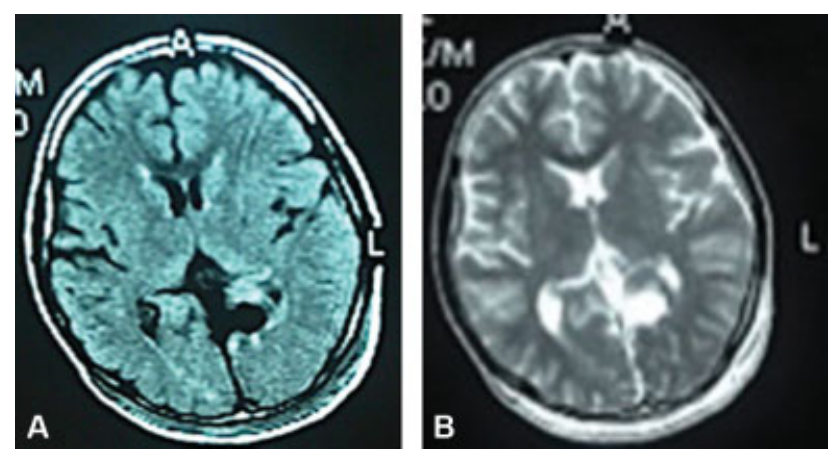

Fig. 3 Postoperative axial magnetic resonance imaging images; A: Flair, B: T 2. showing the total resection of the cerebral cavernous malformation, with intact surrounding cortex.

although with variable penetrance and presentation. Culprit genes include CCM1 (KRIT 1), CCM2 and CCM3. Loss-offunction mutations in these genes lead to derangements in cerebral endothelial cells signaling pathways. ${ }^{10-12}$ Sporadic CMMs may arise de novo or secondary to radiation therapy, stereotactic radiosurgery, and brain biopsy. ${ }^{13,14}$ Sporadic CMMs are often solitary and are more likely to be associated with developmental venous anomalies (DVAs). ${ }^{9}$

Cerebral cavernous malformations may present with seizures, focal neurological deficits or be detected as an incidental finding. The annual risk of hemorrhage is $3 \%{ }^{15}$ The diagnosis of CCMs is confirmed by MRI. The use of catheter angiography is not recommended, as these lesions are devoid of blood flow and are hence "angiographically occult" 9,14 . However, $10 \%$ of CCMs may appear as "capillary brush," mimicking meningiomas. ${ }^{9,14}$ Hemorrhagic cerebral metastases, especially those originating from melanomas and renal cell carcinomas, can also give a similar appearance to CCMs on MRI; however, these lesions are more likely to be junctional and heterogeneously enhancing; they also tend to have more surrounding cerebral edema. ${ }^{9}$
The management approach for CCMs is based on the risk of recurrent hemorrhage. In 2016, a systematic review that included 1,620 patients with CCMs reported a $15.8 \%$ (95\% confidence interval [CI]: 13.7-17.9) risk of symptomatic intracranial hemorrhage (ICH). ${ }^{16}$ Lesions associated with DVAs carry a higher risk of symptomatic ICH. ${ }^{17}$ However, factors such as multiplicity, age, and gender had no independent prognostic significance. ${ }^{16}$ Asymptomatic CCMs are managed conservatively with annual follow-ups. ${ }^{10}$ Some experts may choose to do yearly MRIs; however, this approach does not alter management. ${ }^{18}$ Rather, an immediate MRI is recommended upon the onset of acute symptoms, such as hemorrhage, seizure, or focal neurological deficit. ${ }^{9}$ Surgical resection of asymptomatic CCMs is sometimes considered to be beneficial in light of psychological, occupational and economic factors. ${ }^{9}$ Factors that influence surgical decision-making include the presence of refractory seizures, recurrent hemorrhages, or progressive neurological deficits, along with lesion-specific characteristics, including size and location. ${ }^{9,19}$ Complications of untreated CCMs include ICH and focal neurological deficits ${ }^{20}$

In 2014, a systematic review and meta-analysis examined the effect of neurosurgical resection in a total of 3,400 patients who were followed-up for a median of 3.3 years. ${ }^{21}$ The primary outcomes were non-fatal stroke, death, and a new-onset progressive focal neurological deficit. ${ }^{21}$ The collective incidence of these outcomes after resection was 6.6 per 100 person-years (95\%CI: 5.7-7.5). ${ }^{21}$

The CCM is a recognized etiology for refractory partial seizures. $^{22}$ Whether the removal of the hemosiderin ring should be performed in addition to the lesionectomy or not is a debatable issue. ${ }^{23}$ However, the outcome of such procedures is, in general, satisfactory. Our case showed the effectiveness of complete CMM resection with its hemosiderin ring. Some studies have suggested that failure of lesionectomy is the only indication for invasive electrophysiological tests apart from the routine EEG. ${ }^{23,24}$ Occipital CCMs, and particularly those located at the medial occipital zone, have intimate correlation with the visual apparatus. The remarkable aspect of our case is the complete resolution of visual symptoms and the achievement of seizure-free status; outcomes that are rarely reported after occipital cavernoma resection. ${ }^{24}$

\section{Conclusion}

Timely and meticulous microsurgical resection of occipital CCMs resulted in overt improvement in vision and satisfactory seizure-control.

Conflict of Interests

The authors have no conflict of interests to declare.

\section{References}

1 Requena I, Arias M, López-Ibor L, et al. Cavernomas of the central nervous system: clinical and neuroimaging manifestations in 47 patients. J Neurol Neurosurg Psychiatry 1991;54(07):590-594

2 Cortés Vela JJ, Concepción Aramendía L, Ballenilla Marco F, Gallego León JI, González-Spínola San Gil J. Cerebral cavernous 
malformations: spectrum of neuroradiological findings. Radiologia (Madr) 2012;54(05):401-409

3 Cohen DS, Zubay GP, Goodman RR. Seizure outcome after lesionectomy for cavernous malformations. J Neurosurg 1995;83(02): 237-242

4 Awad I, Jabbour P. Cerebral cavernous malformations and epilepsy. Neurosurg Focus 2006;21(01):e7

5 Awad IA, Robinson JR. Cavernous malformations and epilepsy, in Awad IA, Barrow DL (eds): Cavernous Malformations. Park Ridge, IL: American Association of Neurological Surgeons; 1993:49-64

6 Menzler K, Chen X, Thiel P, et al. Epileptogenicity of cavernomas depends on (archi-) cortical localization. Neurosurgery 2010;67 (04):918-924

7 Russel DS, Rubinstein LJ. 1989Tumours and hamartomas of the blood vessels. In: The pathology of tumours of the nervous system, 5th edn Edward Arnold, London727-790

8 Robinson JR, Awad IA, Little JR. Natural history of the cavernous angioma. J Neurosurg 1991;75(05):709-714

9 Del Curling O Jr, Kelly DL Jr, Elster AD, Craven TE. An analysis of the natural history of cavernous angiomas. J Neurosurg 1991;75(05): 702-708

10 Gomori JM, Grossman RI, Goldberg HI, Hackney DB, Zimmerman RA, Bilaniuk LT. Occult cerebral vascular malformations: highfield MR imaging. Radiology 1986;158(03):707-713

11 Ferroli P, Casazza M, Marras C, Mendola C, Franzini A, Broggi G. Cerebral cavernomas and seizures: a retrospective study on 163 patients who underwent pure lesionectomy. Neurol Sci 2006;26 (06):390-394

12 Kahane P, Munari C, Hoffmann D, et al. Approche chirurgicale multimodale des angiomes caverneux épileptogènes. Epilepsies 1994;6:113-130

13 Kivelev J, Koskela E, Setälä K, Niemelä M, Hernesniemi J. Longterm visual outcome after microsurgical removal of occipital lobe cavernomas. J Neurosurg 2012;117(02):295-301

14 Akers A, Al-Shahi Salman R, A Awad I, et al. Synopsis of Guidelines for the Clinical Management of Cerebral Cavernous Mal- formations: Consensus Recommendations Based on Systematic Literature Review by the Angioma Alliance Scientific Advisory Board Clinical Experts Panel. Neurosurgery 2017;80(05): 665-680

15 Zafar A, Quadri SA, Farooqui M, et al. Familial Cerebral Cavernous Malformations. Stroke 2019;50(05):1294-1301

$16 \mathrm{Kim}$ J. Introduction to cerebral cavernous malformation: a brief review. BMB Rep 2016;49(05):255-262

17 Choquet H, Pawlikowska L, Lawton MT, Kim H. Genetics of cerebral cavernous malformations: current status and future prospects. J Neurosurg Sci 2015;59(03):211-220

18 Winkler EA, Rutledge C, Ward M, et al. Radiation-induced Cavernous Malformation as a Late Sequelae of Stereotactic Radiosurgery for Epilepsy. Cureus 2018;10(03):e2308-e2308

19 Fritschi JA, Reulen HJ, Spetzler RF, Zabramski JM. Cavernous malformations of the brain stem. A review of 139 cases. Acta Neurochir (Wien) 1994;130(1-4):35-46

20 Horne MA, Flemming KD, Su ICCerebral Cavernous Malformations Individual Patient Data Meta-analysis Collaborators, et al . Clinical course of untreated cerebral cavernous malformations: a metaanalysis of individual patient data. Lancet Neurol 2016;15(02): 166-173

21 Poorthuis MH, Klijn CJ, Algra A, Rinkel GJ, Al-Shahi Salman R. Treatment of cerebral cavernous malformations: a systematic review and meta-regression analysis. J Neurol Neurosurg Psychiatry 2014;85(12):1319-1323

22 Kamezawa T, Hamada J, Niiro M, Kai Y, Ishimaru K, Kuratsu J. Clinical implications of associated venous drainage in patients with cavernous malformation. J Neurosurg 2005;102(01):24-28

23 Mouchtouris N, Chalouhi N, Chitale A, et al. Management of cerebral cavernous malformations: from diagnosis to treatment. ScientificWorldJournal 2015;2015:808314

24 Chohan MO, Marchiò S, Morrison LA, et al. Emerging Pharmacologic Targets in Cerebral Cavernous Malformation and Potential Strategies to Alter the Natural History of a Difficult Disease: A Review. JAMA Neurol 2019;76(04):492-500 